\title{
ASPECTOS TECTÔNICOS FUNDAMENTAIS DO PROTEROZÓICO MÉDIO NA AMAZÔNIA BRASILEIRA
}

\author{
JOÃO B.S. COSTA* \& YOCITERU HASUI**
}

\begin{abstract}
FUNDAMENTAL MIDDLE PROTEROZOIC TECTONIC FEATURES AT THE BRAZILIAN AMAZON REGION. The varied volcanic, plutonic and sedimentary rocks of Middle Proterozoic age are related to an extensional thermo-tectonic event which affected all the Brazilian Amazon region. The geometry and cinematics of the structural features and the basin fillings allowed to recognize two major extensional compartments. Several sets of NW-SE to WNW-ESE-trending normal faults with dips towards NE in the Eastern Compartment are observed, which formed many half-grabens; some normal faults are inclined to $\mathrm{SW}$ and form local symmetric grabens, like that of the Cachimbo. The transfer faults have consistent NE-SW direction, parallel to the extension axis. The K-Ar and $\mathrm{Rb}-\mathrm{Sr}$ radiometric data point out younger ages from NE to SW, what is seen as due to the propagation of the normal faults by footwall collapse in that sense. The Western Compartment has normal faults sets with E-W direction, mostly dipping to $\mathrm{N}$. The transfer faults have N-S trend, parallel to the direction of the extension axis. As the lithologic units present younging from $S$ to $N$, one may infer the development of the fault system by hanging-wall collapse in that sense. The Eastern and Western Compartments are separated by the Boa Vista-Caracaraí Transfer Zone. The normal faults of both compartments and the Boa Vista-Caracaraí Transfer Zone have coincident trends with the direction of earlier basement anisotropies. Such observation supports a reactivation of pre-existent structures as an important factor for the extensional movements and lithospheric thinning. The nature and volume of magmatic rocks associated to the several basins indicate that the lithospheric stretching factor was higher than 2 , but lower than 5 , and it did not reach the value necessary for generation of oceanic crust. The extensional event inverted to a compressive one at the beggining of the Upper Proterozoic, more noticeable in the Western Compartment. The normal faults were reactivated as upthrusts and the transfer zones as lateral ramps.
\end{abstract}

Keywords: Middle Proterozoic, Amazon, sedimentary basin, extensional tectonics, Boa Vista-Caracaraí transfer zone, western compartment, eastern compartment.

\begin{abstract}
RESUMO As variadas rochas vulcânicas, plutônicas e sedimentares do Proteroz6ico Médio da Amazônia brasileira relacionam-se com um evento termo-tectônico distensivo de abrangência regional. A geometria e a cinemática dos elementos estruturais e a natureza das unidades sedimentares permitem individualizar dois compartimentos extensionais principais. O Compartimento Oriental compreende vários feixes de falhas normais de direções NW-SE e WNW-ESE e mergulhos para NE, que compõem a arquitetura das bacias de tipo hemigráben; falhas normais inclinadas para SW definem, localmente, estruturas simétricas, como o Gráben do Cachimbo. As falhas de transferência orientam-se sistematicamente na direção NE-SW. Os dados geocronológicos disponíveis sugerem idades dos litotipos cada vez mais jovens de NE para SW, indicando que a movimentação extensional progrediu de NE para SW, por colapso da lapa (piso). O Compartimento Ocidental inclui feixes de falhas normais $\mathrm{E}-\mathrm{W}$ inclinadas preferencialmente para $\mathrm{N}$ e falhas de transferência orientadas na direção $\mathrm{N}$-S. Como as unidades litológicas tornam-se mais jovens à medida que se caminha para norte, pode-se deduzir que a progressão da deformação envolveu colapso da capa (teto). Os dois compartimentos articulam-se através da Zona de Transferência Boa Vista-Caracaraí. Os feixes de falhas normais nos dois compartimentos, bem como a Zona de Transferência Boa Vista-Caracaraí, têm direções coincidentes com as das anisotropias preexistentes do embasamento das bacias, indicando a reativação de estruturas antigas como um aspecto importante da tectônica distensiva e do adelgaçamento litosférico. A julgar pela natureza e volume de material magmático acumulado nas diversas bacias, conclui-se que o fator de estiramento foi superior a 2, mas não alcançou 5, esperado em estágios de formação de crosta oceânica. Esse evento extensional do Proterozóico Médio inverteu para compressão no limiar do Proterozóico Superior, em particular no Compartimento Ocidental. As falhas normais foram reativadas em cavalgamentos e as zonas de transferência funcionaram como lanços laterais.
\end{abstract}

Palavras-chaves: Proterozóico Médio, Amazônia, bacias sedimentares, tectônica distensiva, Zona de Transferência Boa Vista-Caracaraí, compartimento ocidental, compartimento oriental.

INTRODUÇÃO

As unidades litológicas mesoproterozóicas da Amazônia brasileira, a oeste da área dos Cinturões Orogênicos Paraguai e Araguaia, são representadas essencialmente por um conjunto de vulcanitos ácidos a intermediários, plutonitos ácidos a básicos e alcalinos, e rochas sedimentares de ambientes continentais e marinhos, formados no intervalo 1,9-0,9 Ga, essencialmente no Proterozóico Médio.

Tais unidades foram descritas em muitos trabalhos, que se dispensa aqui relacionar, e algumas sínteses foram já apresentadas (p. ex., Gibbs \& Barron 1983, Hasui \& Almeida 1985). O exame do acervo de informações mostra a existência de designações variadas apresentadas para unidades de áreas diversas, bem como correlações distintas, em geral com base em comparações de litotipos e/ou levando em conta dados radiométricos, na maior parte preliminares, apresentados pelo Projeto Radam, e alguns trabalhos posteriores. Essa situação reflete o nível geral ainda de reconhecimento de abordagem de tais unidades dispersas ao longo de vastíssima extensão territorial de difícil acesso e a elaboração de um quadro estratigráfico regional que necessariamente requer ainda a introdução de critérios subjetivos; as discussões nesse sentido já foram levadas até a exaustão em numerosos trabalhos publicados, sem alcançarem consenso, por falta de dados mais acurados, não cabendo aqui retomá-la.

Independentemente das controvérsias e dispensando-se a apresentação de mais uma proposta estratigráfica, todos os familiarizados com a realidade do terreno reconhecem que a geração de tais unidades envolveu movimentação de falhas, formação de bacias por abatimentos de blocos e ascensão de materiais magmáticos, sob a égide de um tectonismo de abrangência regional. 
Por meio dessas manifestações, pode-se caracterizar esse tectonismo que atuou durante o Proterozóico Médio na Amazônia brasileira, à luz dos modernos conceitos. Este trabalho tem por objetivo abordar algumas feições reconhecidas mais recentemente em trabalhos de campo, em termos da evolução tectono-magmática-sedimentar regional.

\section{O QUADRO TECTÔNICO DELINEADO EM TRABA- LHOS ANTERIORES Os falhamentos, os embaciamen-} tos com preenchimentos sedimentares ou vulcanossedimentares, o vulcanismo ácido/intermediário, o plutonismo ácido/ básico e alcalino do Proterozóico Médio são vistos como manifestações de processos tectônicos que, em trabalhos anteriores, foram apenas esboçados em seus traços mais gerais e de modos diferentes. As várias propostas de interpretação giram em torno de duas concepções básicas.

Numa primeira visão, o proterozóico médio da Amazônia brasileira foi considerado em termos de um tipo novo de manifestação tectônica na história do planeta, referido como de reativação de plataforma, afetando o megacontinente mesoproterozóico: a plataforma, que se consolidara antes, teria sido afetada por um evento há 1,7 - 1,4 Ga e outro análogo teria ocorrido na região de Rondônia, em torno de $1,0 \mathrm{Ga}$ (Almeida 1974). Em seguida, com novos dados geocronológicos, os referidos processos foram interpretados em termos de três eventos: Paraense $(1,7-1,5 \mathrm{Ga})$, Madeirense $(1,4-1,2 \mathrm{Ga}) \mathrm{e}$ Rondoniense $(1,0-0,9 \mathrm{Ga})$, separados por intervalos de estabilidade tectônica e incidindo em faixas largas e longas de direção NW-SE, com migração dos processos de NE para SW (Amaral 1974). Posteriormente, esses três eventos tectônicos foram considerados como marcos de épocas de recrudescimento de um único evento distensivo intraplaca de longa duração (Issler \& Lima 1987).

Os processos atribuídos à reativação de plataforma são aqueles que se relacionam com a primeira metade do Ciclo de Wilson (soerguimento e rifteamento que progridem até abertura de oceano), envolvendo elevação de isotermas, criação de relevo, instabilização tectônica, deslocamentos horizontais de massas crustais e mobilização magmática; como tais, eles devem ser vinculados a efeitos de plumas do manto. Com base nessa visão, Bridgwater et al. (1974) consideraram uma megapluma mantélica para explicar os processos ocorridos no Hemisfério Norte durante o Proterozóico Médio, análogos aos da mesma era na Amazônia, como já observara Almeida (1974), sem chegar ao estágio de abertura oceânica. Esse modelo foi evocado para explicar o quadro regional aqui em pauta (Hasui et al. 1984) e nessa concepção a tectônica é do tipo distensivo.

Uma interpretação diferente foi aventada em termos de cinturões móveis (Cordani et al. 1979, Cordani \& Neves 1982), admitindo a possível existência de um núcleo arqueano (Província da Amazônia Central), em torno do qual se teriam desenvolvido o Cinturão Maroni-Itacaiunas a nordeste e norte $(2,2-1,8 \mathrm{Ga})$, o Cinturão Rio Negro-Juruena a sudoeste $(1,7-1,4 \mathrm{Ga})$ e o Cinturão Rondoniano mais a sudoeste (1,4 - 1,0 Ga). A Província da Amazônia Central teria tido comportamento paraplataformal em eventos de reativação reflexa ligados ao desenvolvimento dos cinturões móveis entre 1,9 e 1,3 Ga. O Cinturão Rondoniano seria ensiálico, representado por supra-crustais mesoproterozóicas e um embasamento retrabalhado, bem como intrusões sin a pós-tectônicas e granitos cratônicos. O Cinturão Rio Negro-Juruena seria formado por rochas grani-tóides, talvez de um arco magmático. Nessa interpretação, os produtos litoestruturais do Proterozóico Médio teriam resultado de eventos sucessivos marcados por regimes distensivos, compressivos e transcorrentes, com os quais os dados de campo não se coadunam.

Especificamente em relação às bacias mesoproteroź́icas, foi apresentada uma tentativa de caracterizá-las tectonicamente (Montalvão et al. 1984). As bacias formadas no intervalo
1,9 - 1,6 Ga teriam se desenvolvido em dois ou três estágios tectônicos: (1) um estágio de rifte ou aulacógeno, com adelgaçamentos crustais, abatimentos de blocos controlados por falhas de altos mergulhos e manifestações magmáticas associadas, seguido de (2) um estágio de sinéclise, com arqueamento lento, para baixo, afetando o domínio do rifte ou aulacógeno e vastas áreas adjacentes e, por fim, (3) um estágio de subsidência muito lenta, ocorrendo em algumas bacias, marcado por coberturas tabulares horizontais ou suborizontais. Por sua vez, as bacias desenvolvidas no intervalo 1,6 - 1,4 Ga corresponderiam a grábens preenchidos por red beds. Essa interpretação assume uma série de premissas e correlações ainda por comprovar.

ESTRUTURAS E TECTÔNICA A análise geométrica e cinemática dos elementos estruturais e as características e distribuição geográfica das unidades litológicas permitem dividir a região da Amazônia brasileira em dois grandes compartimentos estruturalmente distintos (Fig. 1), referidos aqui como Oriental e Ocidental.

\section{Compartimento Oriental O Compartimento Oriental} foi descrito por Costa et al. (1991a). É limitado pelo Cinturão Araguaia, a leste, pelos sedimentos da ilha do Bananal, a sudeste e pela Zona de Transferência Boa Vista-Caracaraí, a noroeste. A Bacia do Amazonas superimpôs-se a esse compartimento, dividindo-o em dois setores.

Sua constituição litológica inclui vulcânicas ácidas/intermediárias enfeixadas no Grupo Uatumã e sedimentos continentais e marinhos reunidos nas Formações Beneficente, Prosperança, Acari, Gorotire e Cubencranquém. Tais unidades encontramse depositadas em bacias assimétricas, mas localmente reconhecem-se grábens simétricos, como o do Cachimbo. Corpos graníticos dos tipos Velho Guilherme, Carajás, Teles Pires etc. associam-se a esse contexto.

A arquitetura geral das bacias é dada por: 1. vários feixes de falhas normais de direções NW-SE e WNWESE e mergulhos voltados para o lado norte, com exceção do feixe da borda nordeste do Gráben do Cachimbo, que mergulha para SW (Fig. 2). As informações obtidas no canto sudeste do compartimento indicam que as falhas normais têm perfis lístricos e afetam tanto o embasamento como as coberturas, sugerindo vários pulsos de movimentação na progressão da distensão. Com base nessa informação, foi admitido o modelo lístrico para os demais feixes de falhas;

2. transcorrências dextrais e sinistrais orientadas preferencialmente nas direções NE-SW e ENE-WSW, que seccionam as falhas normais $\mathrm{e}$ as diferentes unidades litológicas.

Indicadores de deslocamentos ao longo das falhas normais estão orientados sistematicamente na direção NE-SW, com variações para ENE-WSW, marcando a direção NE-SW do eixo extensional. $O$ padrão de fraturas de cisalhamento associadas sugere a atuação de um binário sinistral de direção em torno de $\mathrm{N}$-S ou, alternativamente, dextral de direção E-W, qualquer dos casos implicando distensão na direção NE-SW. Nesse contexto, as fallhas transcorrentes NE-SW devem representar acomodações na direção de estiramento máximo e podem ser classificadas como falhas de transferência (Gibbs 1984).

As datações existentes indicam que as unidades litológicas desse compartimento, no geral, são mais jovenns de NE para SW. Como a direção do eixo extensional é aproximadamente NE-SW, deduz-se que as bacias evoluiram de NE para SW, obviamente através do modelo de colapso da lapa (ou piso) e pode-se falar em adelgaçamento litosférico progredindo $\mathrm{em}$ direção a SW.

Na região do Cachimbo, há registros de empurrões e de amplas dobras associadas (Lima 1986), que, ao invés de serem atectônicas, como sugerido por Montalvão et al. (1984), indicam que o Compartimento Oriental experimentou inversão positiva fraca a moderada (Fig. 3). 


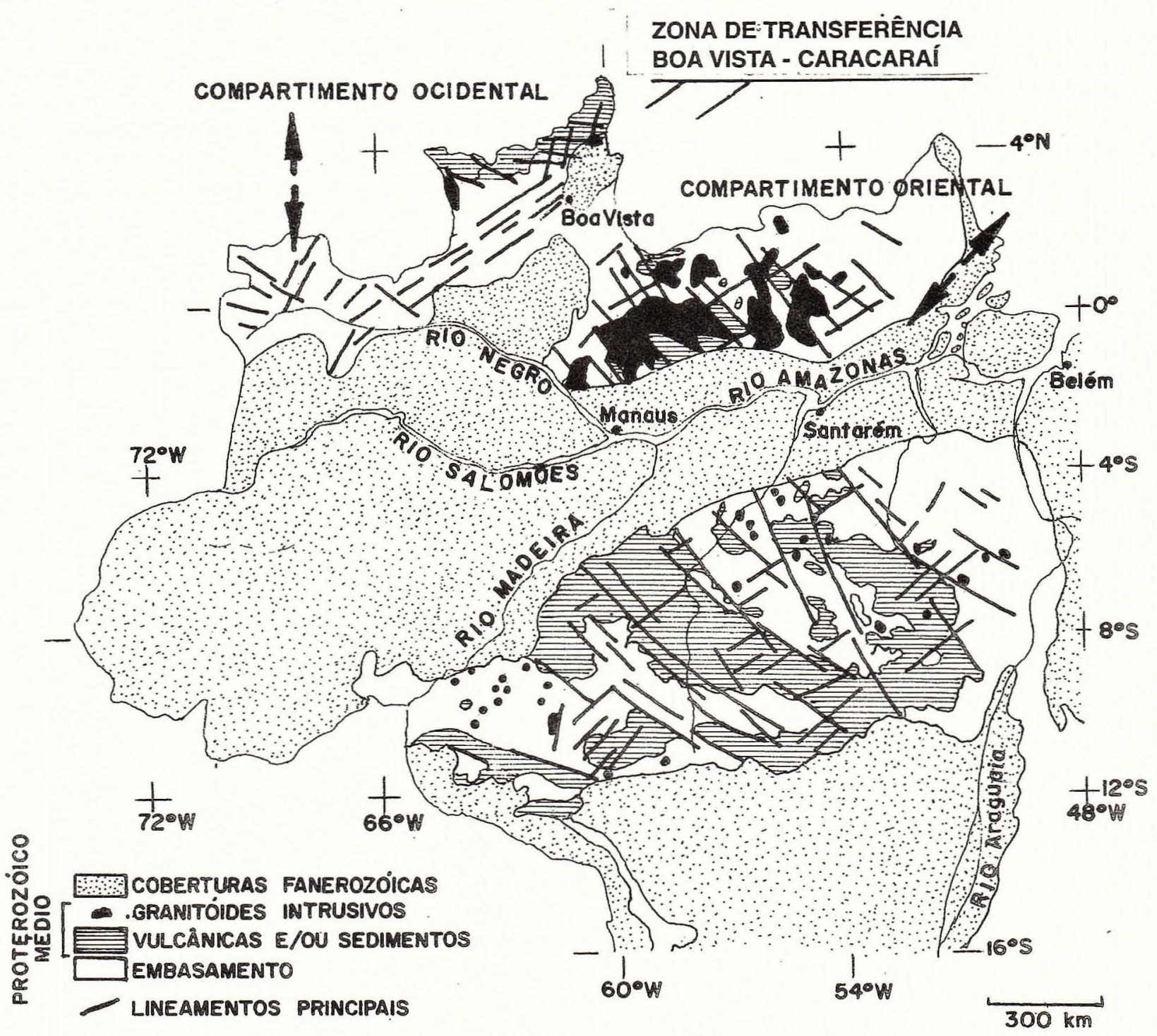

Figura 1-Mapa geológico simplificado do Proterozóico Médio da Amazônia brasileira. As setas indicam a direções de distensão nos dois compartimentos separados pela Zona de Transferência Boa Vista-Caracaraí

Figure 1 - Simplifield geologic map of the Middle Proterozoic of the Brazilian Amazon. The arrows indicate extension trends in both compartments which are separated by the Boa Vista-Caracaraí

Compartimento Ocidental O Compartimento Ocidental foi descrito por Costa et al. (1991b). É limitado a sudeste pela Zona de Transferência Boa Vista-Caracaraí, tendo continuidade nos países vizinhos a norte e nordeste. Suas unidades litológicas são granitos e rochas vulcânicas do Grupo Surumu e sedimentos do Supergrupo Roraima.

Os elementos estruturais que definem a geometria interna desse compartimento, presentes tanto nas unidades formadas durante a movimentação extensional quanto no embasamento, são feixes de lineamentos orientados nas direções E-W e WNW-ESE, que correspondem a falhas normais e cavalgamentos rúptil-dúcteis. Nesse caso, as depressões que acolheram os produtos litológicos desse compartimento encontram-se invertidas.

Nos locais onde a inversão não foi acentuada, em particular na parte norte do compartimento, reconhecem-se falhas normais inclinadas sistematicamente para $\mathrm{N}$, mas há falhas menores mergulhando para $\mathrm{S}$. Verifica-se também que outras feições ligadas a distensão ainda podem ser caracterizadas, como a discordância entre os sedimentos Roraima e as rochas vulcânicas Surumu, bem como as direções de paleocorrentes dos sedimentos marinhos da Formação Verde. O exercício de restauração das relações geométricas entre as unidades litológicas durante a distensão e da arquitetura das bacias é ilustrado na figura 4. O modelo que melhor se ajusta às observações de campo envolve colapso da capa (ou teto), isto é, individualização progressiva do gráben de S para N. Nesse quadro, as falhas transcorrentes N-S representam zonas de transferência.

A ausência de rochas vulcânicas Surumu na região centronorte da Venezuela e a simetria dos sistemas fluviais do Supergrupo Roraima sugerem a implantação de bacias inicialmente assimétricas que, depois, evoluíram para grábens na progressão da deformação para $\mathrm{N}$ (Fig. 5).

As estruturas de inversão são representadas por cavalgamentos rúptil-dúcteis, presentes em particular nas interfaces dos conjuntos embasamento/Surumu e Surumu/Roraima. A movimentação associada aos planos' de deformação concentrada impôs dobramentos e deslocamentos de $\mathrm{N}$ para $\mathrm{S}$ nos pacotes 
vulcânicos e sedimentares (Fig. 6). Dentro das zonas de cavalgamento, as rochas sofreram transformações mineralógicas em fácies xisto-verde e ganharam uma foliação incipiente. As mesmas características mineralógicas e estruturais são vistas nas rochas ao longo das falhas transcorrentes $\mathrm{N}-\mathrm{S}$, indicando que as falhas de transferência funcionaram como rampas (ou lanços) laterais durante a inversão positiva fraca a moderada.

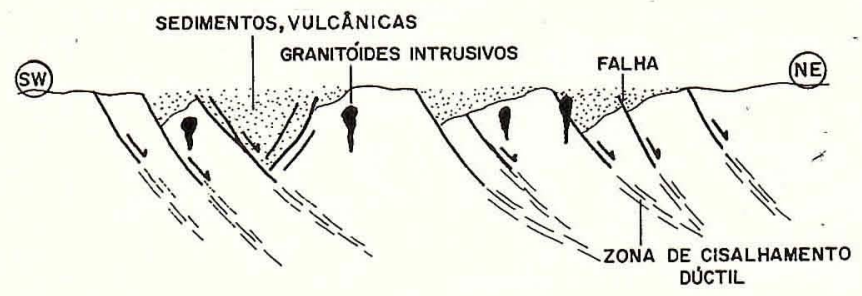

Figura 2 - Seção esquemática ilustrando a arquitetura crustal da fase extensional mesoproterozóica do Compartimento Oriental. Modificado de Costa et al. (1991a). Sem escala

Figure 2 - Schematic section showing the crustal architecture of the Middle Proterozoic extensions phase of the eastern compartiment. Modified from Costa et al. (1991a). Without scale

Nos locais onde os cavalgamentos são numerosos e pouco espaçados, como nas adjacências da Vila Mutum, a deformação é acomodada através de dobras que variam de abertas, com topo chato ou não, a isoclinais.

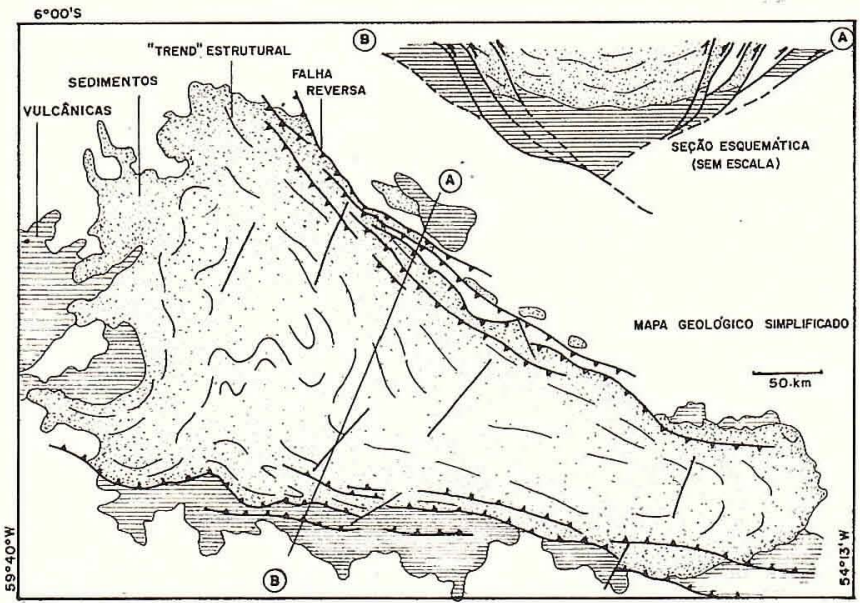

Figura 3-Mapa geológico simplificado da região da Chapada do Cachimbo. A seção $A B$ esquematiza a geometria da bacia invertida. Modificado de Lima (1986)

Figure 3 - Simplified geologic map of the Cachimbo region. The AB section shows the geometry of the inverted basin. Modified from Lima (1986)

\section{Relações entre os compartimentos As diferenças} estruturais entre os dois compartimentos são, resumidamente: 1. no Compartimento Oriental, as falhas normais evoluíram por colapso do piso, com um eixo extensional de orientação NE-SW. No Compartimento Ocidental, o eixo extensional foi submeridiano e as falhas normais desenvolveram-se de S para $\mathrm{N}$, seguindo o modelo de colapso do teto;

2. as estruturas extensionais do Compartimento Ocidental foram reativadas em cavalgamentos no final do Proterozóico
Médio, enquanto a movimentação extensional avançava para SW no Compartimento Oriental, mas, neste, em seguida, também ocorreu inversão positiva;

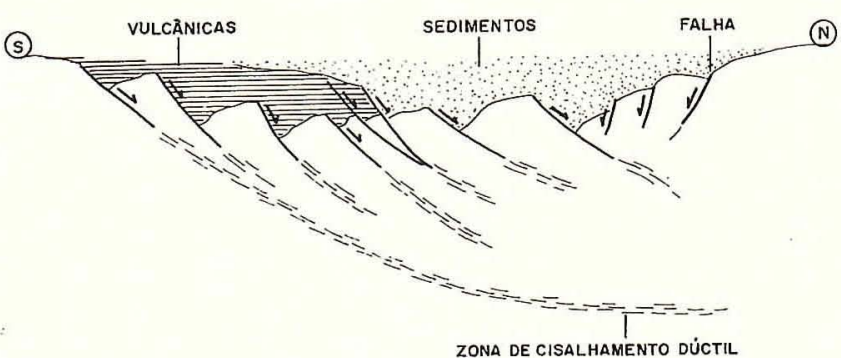

Figura 4-Seção esquemática ilustrando a geometria da bacia que acolheu as rochas vulcânicas Surumu e os sedimentos Roraima no Compartimento Ocidental em Roraima. Modificado de Costa et al. (1991b)

Figure 4 - Schematic section showing the geometry of the basin where the Surumu volcanic rocks were extruded and the Roraima sediments were deposited in the western compartment of Roraima. Modified from Costa et al. (1991b)

3. em termos litológicos, há diferenças importantes entre os produtos sedimentares dos dois compartimentos. O Grupo Beneficente e a Formação Acari incluem registros de plataforma carbonática que parece ter ocupado a parte oeste do Compartimento Oriental; o Supergrupo Roraima tem na sua constituição expressivos produtos de um sistema marinho caracterizando vários ciclos de tansgressão-regressão.

O limite entre os sistema estruturais e deposicionais mencionados é marcado pelo feixe de lineamentos NE-SW ao longo da Faixa Boa Vista-Caracaraí, que funcionou como um anteparo natural na evolução litoestrutural dos dois compartimentos. Esse feixe, nesse contexto, é entendido como uma zona de transferência.

\section{FUSÃO PARCIAL $x$ ADELGACAMENTO LITOSFÉ-} RICO Nos últimos anos, tem sido mostrado que a produção de rochas ígneas em regimes extensionais depende do fator de estiramento B ou da taxa de adelgaçamento da litosfera 1/B (Bosworth 1985, Keen 1985, 1987).

O processo de adelgaçamento litosférico implica subida da astenosfera e conseqüente elevação de isotermas. Na progressão da deformação, com valor 1,56 para B, a base da litosfera alcança profundidades da ordem de $75 \mathrm{~km}$ e magmas são gerados a partir da fusão parcial da astenosfera, em decorrência da diminuição da pressão e manutenção de altas temperaturas . Valores de $\mathrm{B}$ superiores a cinco implicam desenvolvimento de crosta oceânica com espessura da ordem de $5 \mathrm{~km}$ (Fig. 3, de Keen 1987).

Sabe-se, também, que as falhas normais dos niveis crustais superiores passam para zonas de cisalhamento dúctil em profundidade, impondo estruturação anastomosada à crosta inferior (p. ex., Wernicke 1985, Coward 1986, Reston 1988). O calor de cisalhamento (shear heating) gerado durante a implantação do feixe de zonas de cisalhamento e o alto gradiente térmico associado à elevação das isotermas, podem também induzir fusão parcial de material crustal. Se a crosta adelgaçada for fortemente anisotrópica, os fundidos produzidos no nivel da crosta inferior e do manto podem migrar e facilmente alcançar a superficie. Tais produtos, juntamente com os sistemas deposicionais implantados, compõem o enchimento das bacias.

Nos compartimentos extensionais da Amazônia brasileira, há expressivos volumes de rochas vulcânicas e plutônicas intimamente associadas ao processo de adelgaçamento da litosfera no Proterozóico Médio. As seqüências vulcânicas são 
dominantemente ácidas/intermediárias e os corpos plutônicos são essencialmente granitóides; corpos máficos também existem, bem como alcalinos e ultramáficos. Grande parte dessas unidades é interpretada como de derivação mantélica, mas há conjuntos que devem ter evoluído a partir de fusão de material crustal.
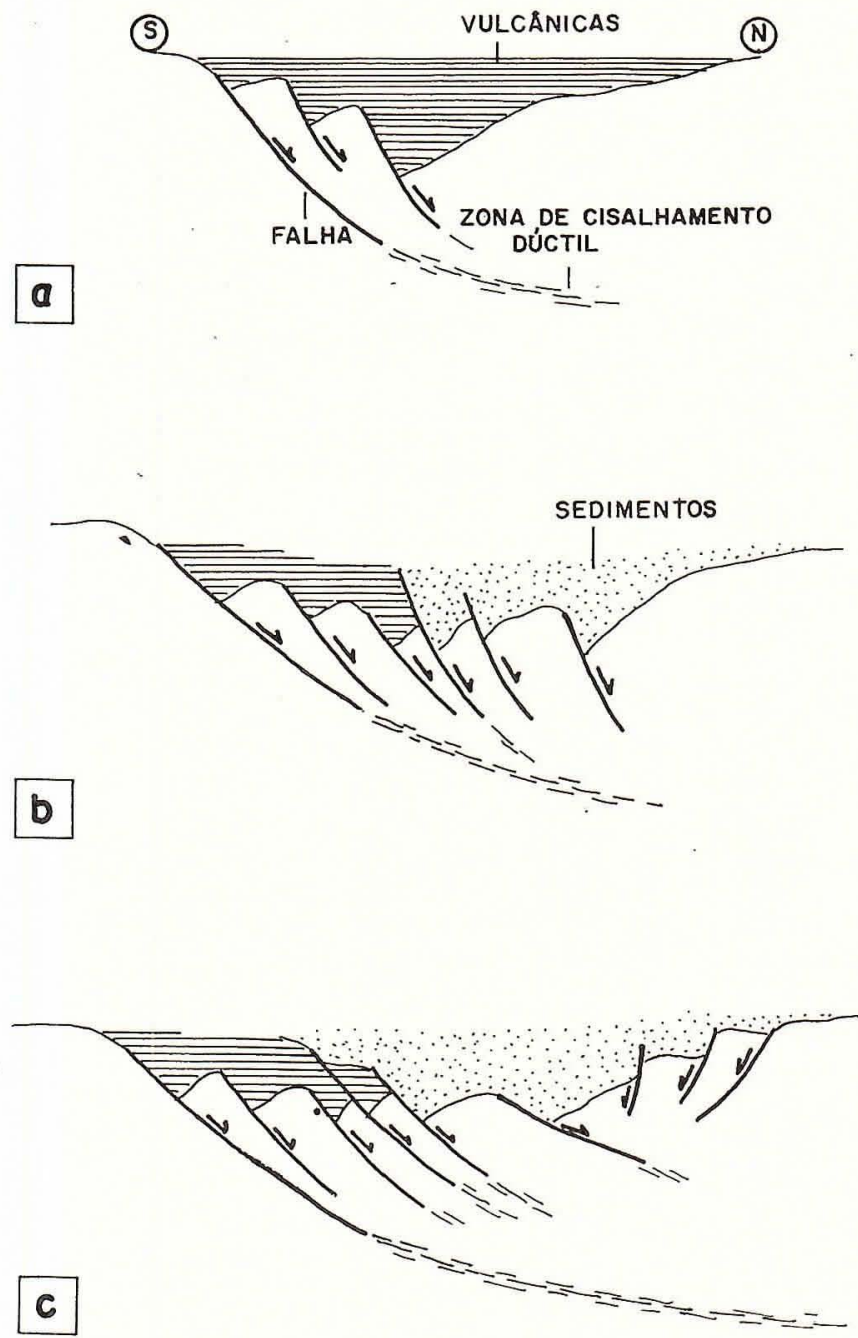

Figura 5 - Esquema de desenvolvimento da Bacia SurumuRoraima por colapso da capa. Etapa a: individualização da bacia e acumulação das rochas vulcânicas Surumu. Etapa b: progressão da deformação para norte, deposição dos sedimentos Roraima e rotação das falhas anteriores. Etapa c: ampliação da Bacia Roraima com desenvolvimento de falhas antitéticas mais ao norte. Sem escala

Figure 5-Sketch of Surumu - Roraima basin evolution through hanging wall collapse. Phase a: individualization of the basin and deposition of the Surumu volcanic rocks. Phase b: progression of the deformation towards the north, deposition of the Roraima sediments and rotation of the older faults. Phase c: expansion of the Roraima basin accompanied by the development of the antithetic faults further north. Without scale

Durante a deformação extensional, a reativação de anisotropias preexistentes, representadas mormente por zonas de cisalhamento dúctil impressas nas rochas do embasamento, facilitou a migração dos produtos ígneos através da crosta. A íntima relação dos corpos granitóides com os sistemas estruturais antigos pode ser facilmente observada nos dois comparti- mentos, a exemplo dos granitos tipo Serrra dos Carajás (Central), Cigano, Antonio Vicente etc., que se instalaram ao longo de sistemas transcorrentes antigos e definem um cordão de corpos com orientação E-W.

As informações atuais não permitem ainda calcular o fator de estiramento e, conseqüientemente, a taxa de adelgaçamento litosférico. No entanto, a natureza do material ígneo presente nos dois compartimentos indica que a magnitude de $B$ não alcançou os valores correspondentes a estágios de formação de crosta oceânica $(>5)$ e, considerando-se o volume de material ígneo produzido, deduz-se que foi superior a 2 .

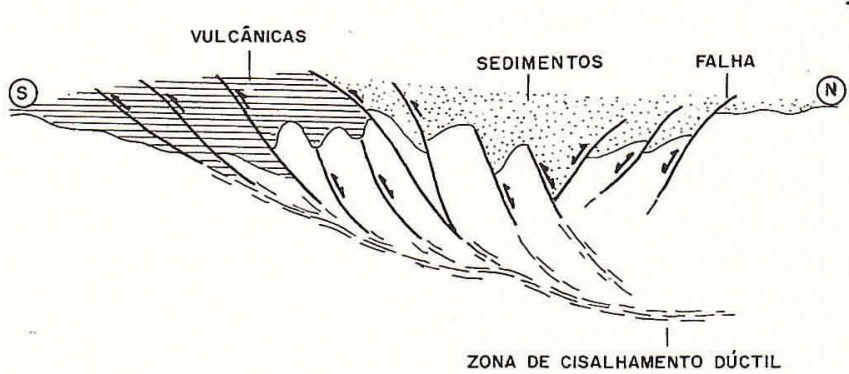

Figura 6 - Seção esquemática ilustrando fase de inversão das Bacias Surumu e Roraima. Modificado de Costa et al. (1991b). Sem escala

Figure 6-Skematic section showing the invertion phase of the Surumu and Roraima basins. Modified from Costa et al. (1991b). Without scale

ESTRUTURAS ANTIGAS $\times$ ESTRUTURAS EXTENSIONAIS A definição dos principais trends estruturais impressos nas rochas do embasamento dos compartimentos extensionais foi conseguida principalmente por meio dos levantamentos geológicos realizados pelas equipes do Projeto Radam na década de 70 e por análises de produtos de sensores remotos. Também, a partir da integração de informações geológicas e geofísicas, foi delineada a megaestruturação da Amazônia em termos de blocos crustais justapostos através de suturas (Hasui et al. 1984). No interior dos blocos, comparecem terrenos granito-greenstone e suas bordas são marcadas por cinturões de cisalhamento que incluem faixas de rochas de alto grau (ver Fig. 5 de Hasui et al. 1984).

As investigações de campo têm mostrado que os cinturões de cisalhamento referidos são de tipo essencialmente dúctil, caracterizados por faixas de deformação concentrada e por transformações mineralógicas sintectônicas de fácies anfibolito a xisto-verde. Nos terrenos granito-greenstone também começou a ser verificado que as relações geométricas entre as principais unidades litológicas são dadas por zonas de cisalhamento dúctil.

Quando são comparadas as orientações das estruturas extensionais do Proterozóico Médio com as zonas e cinturões de cisalhamento dúctil mais antigos, constata-se perfeita coincidência entre os dois conjuntos. As estruturas do Compartimento Oriental ajustam-se ao trend das faixas granulíticas NW-SE a WNW-ESE; no Compartimento Ocidental, o quadro parece ser semelhante, com falhas E-W e N-S inseríveis no contexto de passagens de estruturas NW-SE (Cinturões Parima e Uaupés) para NE-SW (Cinturão Guiana Central).

A zona que separa os dois compartimentos, como dito acima, corresponde a um feixe de zonas de cisalhamento dúctil, com orientação NE-SW, fortemente afetada por processos cataclásticos.

Constata-se que as linhas extensionais devem ter evoluído a partir da reativação dos feixes de zonas de cisalhamento dúctil e a organização estrutural dos compartimentos, com seus eixos extensionais próprios, foi controlada pela geometria 
das estruturas do embasamento. Nessa análise, ainda é previsível que a Bacia do Amazonas tenha sido edificada sobre um feixe de zonas de cisalhamento dúctil antigo, como apontaram Hasui et al. (1984), o qual pode ter funcionado como uma zona de transferência no Proterozóico Médio, dividindo o Compartimento Oriental em dois setores, mas faltam ainda dados para distinguí-los.

Essa interpretação dos movimentos condicionados por estruturas preexistentes é coerente com os estudos experimentais que demonstraram ser as zonas miloníticas de fácil reativação por causa da baixa resistência mecânica decorrente da penetratividade das estruturas planares e da forte cominuição associada à sua formação (White 1976, White et al. 1986, Etheridge 1986).

CONCLUSÕES Conquanto as informações sejam ainda poucas em relação à vastidão da Amazônia brasileira, aquelas existentes já permitem tecer algumas considerações sobre o modelo tectônico do Proterozóico Médio.

As diferenças geométricas e cinemáticas entre os compartimentos extensionais devem-se em parte à presença da Zona de Transferência Boa Vista-Caracaraí, que funcionou como um anteparo natural de partição da deformação. Feição semelhante pode ter existido na região onde se implantou a Bacia do Amazonas, mas faltam dados para defini-la e caracterizar o setor a norte dela. Numerosas falhas menores devem representar feições de acomodação a deslocamentos de blocos no inte-rior dos compartimentos.

O modelo cinemático explica a distribução geográfica das unidades litológicas e envolve o colapso progressivo do piso e do teto, respectivamente nos Compatimentos Oriental e Ocidental.
Os dados geocronológicos existentes sugerem que esse evento extensional iniciou ao redor de $1,9 \mathrm{Ga}$ e prosseguiu até 1,4 Ga no Compartimento Ocidental e até 0,9 Ga no Compartimento Oriental da Amazônia brasileira. No final do Proterozóico Médio, o Compartimento Ocidental experimentou compressão, enquanto o movimento extensional ainda progredia para SW no Compartimento Oriental e, provavelmente, já no limiar do Proterozóico Superior, neste último ocorreu inversão.

Os produtos litológicos indicam que as isotermas subiram abaixo da área que sofreu subsidência tectônica e o adelgaçamento litosférico não alcançou taxas compativeis com os estágios de oceanização, mas B foi superior a 2 .

Algumas particularidades sustentam o modelo que considera o adelgaçamento da crosta e do manto litosférico imediatamente abaixo da área que sofreu a subsidência tectônica, como: 1. há fortes evidências a favor de que a geometria das estruturas extensionais foi muito controlada por anisotropias antigas impressas no embasamento;

2. as áreas onde se implantaram as bacias extensionais coincidem com as regiões intensamente percoladas por produtos ígneos;

3. não há registros de unidades sedimentares tabulares isentas de deformação e de produtos vulcânicos associados fora das áreas que sofreram subsidência tectônica, isto é, não há evidência de subsidência termal ou rebaixamento de isotermas em direção ao N e NE nos compartimentos Ocidental e Oriental, respectivamente.

Nesse modelo de adelgaçamento, as estruturas extensionais devem passar em profundidade para zonas de cisalhamento impondo um padrão lenticularizado à crosta inferior, semelhante ao descrito por Reston (1988) para o nororeste da Europa.

\section{REFERÊNCIAS BIBLIOGRÁFICAS}

ALMEIDA, F.F.M. 1974. Evolução tectônica do Cráton do Guaporé comparada com a do Escudo Báltico. Rev. Bras. Geoc., 4(3):191-204.

AMARAL, G. 1974. Geologia Pré-Cambriana da Região Amazônica. São Paulo. (Tese de Livre Docência, IGIUSP).

BOSWORTH, J. 1985. Geometry of propagating continental rifts. Nature, 316:625-627.

BRIDGWATER, D; SUTTON, J.; WATERSON, J. 1974. Crustal downfolding associated with igneous activity. Tectonophysics, 21:57-77.

CORDANI, U.G. \& NEVES, B.B.B. 1982. The geologic evolution of South America during the Archean and Early Proterozoic. Rev. Bras. Geoc., 12(1-3):78-88.

CORDANI, U.G.; TASSINARI, C.G.; TEIXEIRA, W.; BASEI, M.A.S.; KAWASHITA, K. 1979. Evolução tectônica da Amazônia com base em dados geocronológicos. In: CONGR. GEOL. CHILENO, 2. Arica, 1979. Actas... Arica. p. J-137-148.

COSTA, J.B.S.; PINHEIRO, R.V.L.; JOÃO, X.S.J.; ARAÚJO, O.J.B. 1991a. Esboço estrutural do Proterozóico Médio da Amazônia Oriental. Rev. Museu Paraense Emílio Goeldi. (No prelo).

COSTA, J.B.S.; REIS, N.J.; PINHEIRO, S.S.; PESSOA, M.R. 1991b. Organização litoestrutural do Proterozóico Médio no extremo norte do Estado de Roraima. In: SIMP. GEOL. AMAZÔNIA, 3. Belém. 1991. Atas... Belém, SBG. p. 179-192.

COWARD, M.P. 1986. Heterogeneous stretching, simple shear and basin development. Earth Planet. Sci. Letters, 80:325-336.

ETHERIDGE, M.A. 1986. On reactivation of extensional fault systems. Phil. Trans. Royal Soc. London, A-317:179-194.

GIBBS, A.D. 1984. Structural evolution of extensional basins. J. Geol. Soc. 141:609-620.

GIBBS, A.K.; BARRON, C.N. 1983. The Guyana Shield reviewed. Episodes, 6(2):7-14.

HASUI, Y. \& ALMEIDA, F.F.M. 1985. The Central Brazil Shield reviewed. Episodes, 8(1):29-37.

HASUI, Y.; HARALYI, N.L.E.; SCHOBBENHAUS, C. 1984. Elementos geofísicos e geológicos da região amazônica: subsídios para o modelo geotectônico. In: SYMP. AMAZÔNICO, 2. Manaus, 1984. Anais... Manaus, DNPM. p. 129-148.

ISSLER, R.S. \& LIMA, M.I.C. 1987. Amazonic Craton (Brazil) granitogenesis and its relation to geotectonic units. Rev. Bras. Geoc., 17(4):426-441.

KEEN, K.C. 1985. Some important consequences of lithospheric extension. In: COWARD, M.P.; DEWEY, J.F.; HANCOCK, P.L. eds. Continental Extensional Tectonics. The Geological Society. p. 67-73 (Special Publication 28).

KEEN, K.C. 1987. The dynamics of rifting: deformation of the lithosphere by active and passive driving forces. Geoph. J. 80:95-120.

LIMA, M.I.C. 1986. Interpretação litoestrutural da Chapada do Cachimbo baseada em imagens de radar e Landsat. In: SIMP. LATINO-AMER. SENSOR. REMOTO. Gramado, 1986. (Separata, s.ed.n.p.).

MONTALVÃO, R.M.G.; BEZERRA, P.E.L.; DRAGO, V.A.;CUNHA, B.C.D. 1984. Cobertura da Plataforma da Amazônia, sua sedimentação e evolução tectônica. In: CONGR. BRAS. GEOL., 33. Rio de Janeiro, 1984. Anais... Rio de Janeiro, SBG. 5:2101-2124.

RESTON, T.J. 1988. Evidence for shear zones in the lower crust offshore Britain. Tectonics, 7(5):929-945.

WERNICKE, B. 1985. Uniform sense of simple shear of the continental lithosphere. Can. J. Earth Sci. 22:108-125.

WHITE, S.N. 1976. The effects of strain on microstructures, fabrics and deformation mechanisms in quartzites. Phil. Trans. Royal Soc. London, A283:69-86.

WHITE, S.N.; BRETAN, P.G.; RUTTER, E.H. 1986. Fault zone reactivation: kinematics and mechanisms. Phil. Trans. Royal Soc. London, A317:81-91.
MANUSCRITO A739

Recebido em 12 de maio de 1992 Revisão do autor em 7 de agosto de 1992 Revisão aceita em 30 de setembro de 1992 